\title{
Asser International Sports Law Centre
}

\author{
Jack Anderson
}

Published online: 19 April 2013

(C) T.M.C. Asser Instituut 2013

Since its inception over a decade ago, The International Sports Law Journal, produced by the Asser International Sports Law Centre, has established itself as a leading periodical in the field. The success of the ISLJ was due, in the main part, to the indefatigable Rob Siekmann but also to the long standing Editorial and Advisory boards. All are thanked profusely for their contribution and support.

From 2013, the ISLJ will have a new "look". That look is not just a changed cover. New Editorial and Advisory boards have been appointed, and we are most grateful to them for accepting our invitation. Further, one of the many benefits of the recent collaborative partnership between T.M.C. Asser Press and Springer-Verlag is that the ISLJ has moved to a transparent and intuitive electronic submission system. This new system not only allows for a more streamlined process for publishing the "hard copy" issues but also facilitates online publishing of articles as soon as they are approved. The Managing Editor, the tireless Karen L. Jones, will continue to drive the journal forward and, as Editor-in-Chief, I will try not to get in the way!

Sports law is a thriving area of the law but as with any emerging branch of law if it is to realise its potential as a discrete topic, it needs to be supported by outstanding academic scholarship. The ISLJ exists to provide a platform for such peer-reviewed research. Indeed, this issue epitomises the diversity and strength of sports law and I thank the authors for the quality of their submissions.

J. Anderson $(\square)$

Belfast, Ireland

e-mail: jack.anderson@qub.ac.uk
Nevertheless, the aim of this journal is to build on this quality and to continue to push on and to move, for instance, beyond commentary that is topical-though sections of the journal will always remain open to comments, opinions and shorter pieces. I hope that the ISLJ will become a home for sports law scholarship that takes a reflective view of broad themes in sports law. Moreover, the journal particularly welcomes pieces that challenge current orthodoxies. Has the World Anti-Doping Code gone too far? Is sport really doing enough about racism and gender discrimination? Is there a need for greater consistency in CAS awards? Do we need a World Anti-Corruption Agency? Is there a genuine commitment in sport to good governance? What is next for sports betting and how will that influence the challenges around match-fixing? Questions abound and the ISLJ is open to writings which address these types of questions in a scholarly and lively fashion.

Moreover, in editing this journal I hope that it is not simply a "sports law journal" but that it is truly "international" in its reach. By international, I mean not just that contributions arrive from multiple jurisdictions (and especially those outside Europe) but also that the ISLJ becomes a forum for something that, arguably, is lacking in current sports law scholarship-genuinely comparative legal analysis, e.g., comparative analysis of EU competition law's attitude to sport and professional sport's experience of US anti-trust law.

Finally, over the next number of years Karen and I will try to sustain the ISLJ as best we can by promoting the journal's visibility, credibility and citations patterns. Thanks to Rob Siekmann, Jan Willem Soek and others, we have a great basis to work on. Some of our ideas in promoting the ISLJ, and sports law scholarship more generally will, likely, appear barmy (mainly my ideas) but some are 
likely to be quite sensible (mainly Karen's ideas); either way please do not hesitate to contact us directly with any suggestion you might have.

I look forward to any thoughts you might have on the future of the ISLJ; for now, I hope that you enjoy the current issue.
Jack Anderson

Editor-in-Chief

International Sports Law Journal

Belfast 